Article

\title{
Fault Diagnosis of Rotor Broken Bar in Induction Motor Based on Successive Variational Mode Decomposition
}

\author{
Xinyue Liu ${ }^{1}$, Yan Yan ${ }^{1, *(1)}$, Kaibo Hu ${ }^{2}$, Shan Zhang ${ }^{2}$, Hongjie $\mathrm{Li}^{3}$, Zhen Zhang ${ }^{4}$ and Tingna Shi ${ }^{1,4} \mathbb{D}$ \\ 1 College of Electrical Engineering, Zhejiang University, Hangzhou 310027, China; liuxinyue@zju.edu.cn (X.L.); \\ tnshi@zju.edu.cn (T.S.) \\ 2 Zhejiang Zheneng Lanxi Power Generation Co., Ltd., Jinhua 321199, China; hukb663873@163.com (K.H.); \\ zhangshan@landideal.com (S.Z.) \\ 3 School of Electrical and Information Engineering, Tianjin University, Tianjin 300072, China; \\ nanmulee@tju.edu.cn \\ 4 Advanced Electrical Equipment Innovation Center, Zhejiang University, Hangzhou 311107, China; \\ zzhen@zju.edu.cn \\ * Correspondence: yan_yan@zju.edu.cn; Tel.: +86-13752223207
}

Citation: Liu, X.; Yan, Y.; Hu, K.; Zhang, S.; Li, H.; Zhang, Z.; Shi, T. Fault Diagnosis of Rotor Broken Bar in Induction Motor Based on Successive Variational Mode Decomposition. Energies 2022, 15, 1196. https:// doi.org/10.3390/en15031196

Academic Editor: Daniel Morinigo-Sotelo

Received: 5 January 2022

Accepted: 1 February 2022

Published: 7 February 2022

Publisher's Note: MDPI stays neutral with regard to jurisdictional claims in published maps and institutional affiliations.

Copyright: (C) 2022 by the authors. Licensee MDPI, Basel, Switzerland. This article is an open access article distributed under the terms and conditions of the Creative Commons Attribution (CC BY) license (https:// creativecommons.org/licenses/by/ $4.0 /)$.

\begin{abstract}
When an induction motor is running at stable speed and low slip, the fault signal of the induction motor's broken bar faults are easily submerged by the power frequency $(50 \mathrm{~Hz})$ signal. Thus, it is difficult to extract fault characteristics. The left-side harmonic component representing the fault characteristics can be distinguished from power frequency owing to V-shaped trajectory of the fault component in time-frequency $(t-f)$ domain during motor startup. This article proposed a scheme to detect broken bar faults and discriminate the severity of faults under starting conditions. In this scheme, successive variable mode decomposition (SVMD) is applied to analyze the stator starting current to extract the fault component, and the signal reconstruction is proposed to maximize the energy of the fault component. Then, the quadratic regression curve method of instantaneous frequency square value of the fault component is utilized to discriminate whether the fault occurs. In addition, according to the feature that the energy of the fault component increases with the fault severity, the energy of the right part of the fault component is proposed to detect the severity of the fault. In this paper, experiments are carried out based on a $5.5 \mathrm{~kW}$ three-pole induction motor. The results show that the scheme proposed in this paper can diagnose the broken bar faults and determine the severity of the fault.
\end{abstract}

Keywords: broken bar faults; induction motor; successive variational mode decomposition (SVMD), quantification of failure severity; starting current

\section{Introduction}

Induction motors have been widely used in various industries due to their advantages, including their cheap price and stable structure. However, poor operating environment and artificial mis-operation in the production process may lead to motor failure, among which broken bar faults are one of the typical failures of motors. In the early stage, the broken bar faults manifest as local fracture of the rotor bar with stress near the broken rotor bar enhancing, then the fault develops into complete broken rotor bar even adjacent bars until the motor whole failure. Therefore, the detection of incipient broken rotor bar is very necessary to reduce economic losses and schedule regular maintenance [1]. The fault frequency of the broken bar faults in the stator current is $f_{\mathrm{b}}=|1-2 s| f$, which is called the left-side harmonic; the left-side harmonic component is the fault component. Many papers have put forward fault detection methods which analyze the stator current in time domain and frequency domain. However, the slip rate $s$ will be low in light load steady-state operation, which leads to the fault frequency being easily submerged by power frequency $f$ [2-4]. When partial broken rotor bars occur, the amplitude of the fault component which 
represents the severity of the fault is weak and easy to be overwhelmed by the noise. In both cases, those methods are rough to perform roles in the diagnosis of the broken bar faults [5-8]. The fault frequency changes regularly from $50 \mathrm{~Hz}$ to 0 to $50 \mathrm{~Hz}$ and emerges a $V$-shape in the $t$ - $f$ domain during the starting process, which is completely different from the $t-f$ feature of power frequency. Consequently, the starting current signal is employed to diagnose the broken bar faults in this article.

Linear time-frequency $(t-f)$ analysis methods such as short-time Fourier transform (STFT) and wavelet transform are widely used to analyze non-stationary signals. Choosing a proper window function in STFT can reduce spectrum leakage to a certain extent, but according to Heisenberg's uncertainty principle, STFT cannot take both time and frequency resolution into account, so the fault frequency trajectory in STFT is fuzzy and decentralized when the start-up time is short [9-11]. In [12], an improvement STFT analysis method was proposed to achieve the entire fault frequency trail under a long starting time, whose $t-f$ resolution is determined by the trajectory slope, but the extraction effect under a short starting time has not been verified. Compared with the STFT, wavelet transform has the advantage of multi-resolution and has a better effect of extracting local features of signals [13] uses continuous wavelet transform to analyze the starting current, and realizes the accurate tracking of the fault frequency. Discrete wavelet transform discretizes the scale parameters by power levels, which can decompose the starting current into multiple sub-signals, and then according to the frequency distribution between the sub-signals to obtain the $(t-f)$ trajectory of the fault frequency. However, the performance of those wavelet transform methods are susceptible to the selection of wavelet bases [14,15]. Quadratic transform analysis methods such as Wigner-Ville distribution (WVD) which has the highest $t-f$ resolution is proposed to solve the problem of insufficient $t-f$ resolution. However, the cross-term interference of WVD appears severely resulting from complex harmonic components in the motor current [16-18]. In addition, adaptive decomposition algorithms such as empirical mode decomposition and empirical wavelet transform have a good performance in the analysis of nonlinear and nonstationary signals. Nevertheless, empirical mode decomposition has the problem of mode mixing, which affects the extraction of the fault component [19-21]. The empirical wavelet transform overcomes the problem of mode mixing, but it is susceptible to noise interference, and the frequency band division of sub-signal is limited by the local maximum of the Fourier spectrum [22,23]. Variational mode decomposition suppresses the problem of mode mixing and is beneficial to narrow band signal decomposition, but the decomposition performance of variational mode decomposition depends on the setting of parameter such as mode and penalty factor. If the setting is inaccurate, the result of extracting the fault component will become descending [24-26]. Successive variational mode decomposition (SVMD) which is improved from variational mode decomposition is an adaptive signal processing method. It decomposes the original signal into a series of intrinsic mode functions by constructing and solving constrained variational problems. SVMD can adaptively determine the number of modes and match the best center frequency through decomposing the signals one by one, which leads to the avoidance of redundant mode extraction, the decline of calculation time, and the improvement of convergence speed [27].

This paper proposes a novel method to diagnosis the broken bar faults and distinguish the severity of broken rotor bar under starting conditions, including partial broken rotor bar and adjacent broken rotor bars. This method is based on the decomposition of the stator starting current in the (t-f) domain using the SVMD then reconstructing the fault component according to the center frequency. The quadratic regression curve of the instantaneous frequency square value of the fault component is utilized to diagnose the broken bar faults. In addition, the energy of the fault signal is employed as a quantitative index for the severity of the broken bar faults. The method proposed in this paper is tested by using experimental data under five different states without measuring motor speed.

This paper is structured as follows. The characteristic analysis of the broken bar faults signal is overviewed in the Section 2. Section 3 introduces the methodology of the 
proposed scheme in detail. The fault diagnosis process is fully illustrated in Section 4 . The application of the proposed scheme and thresholds determination are particularly discussed in Section 5. Finally, the conclusion is presented in Section 6.

\section{Analysis on the Fault Features of Broken Bar Faults}

When broken bar faults occur in an induction motor, the distorted rotor magnetic field can be decomposed into a positive and a negative sequence rotating magnetic field. The negative sequence rotating magnetic field induces fault component with a frequency of $f_{\mathrm{b}}=(1-2 s) f$ in the stator winding. The occurrence of the fault component is an important feature of the broken bar faults. The stator current of the motor with broken bar faults is divided into three parts: the power frequency component, the fault component, and the noise. WE assume that the expression of stator current when broken bar faults occur is as follows:

$$
i(t)=A_{p} \cos \left(\omega_{1} t+\varphi_{p}\right)+A_{L} \cos \left[(1-2 s) \omega_{1} t+\varphi_{L}\right]+N(t)
$$

where $A_{p}$ is the power frequency current amplitude, $A_{L}$ is the fault current amplitude under partial broken bar faults, $\omega_{1}$ is the power frequency angular frequency, $\varphi_{p}$ and $\varphi_{L}$ are the phase angles, and $N(t)$ is $35 \mathrm{~dB}$ (signal-to-noise ratio) additive noise.

The time-domain waveform of Equation (1) is shown in Figure 1a, and the power spectral density is shown in Figure 1b. It can be seen that the energy of the power frequency current is concentrated around the power frequency, which is a narrow-band signal. During the starting process, $s$ decreases from 1 to close to 0 with time. The energy of the fault current is dispersed in the frequency band below the power frequency, which is a broadband signal. The power frequency current and the fault current show different characteristics during the starting process, so the starting current can be utilized for the fault diagnosis of broken rotor bars when the slip is low. It can be seen from Figure 1 that the noise is randomly distributed in the frequency domain and the energy is not concentrated. In the early stage of the broken bar faults, the amplitude of the fault component is comparable to the noise component, hence the weak fault current signal is easily submerged by the noise, which brings difficulty to the fault diagnosis. Therefore, this paper takes advantages of the good anti-interference and adaptability of the SVMD to decompose the starting current and takes the fault component as the feature for fault diagnosis. 

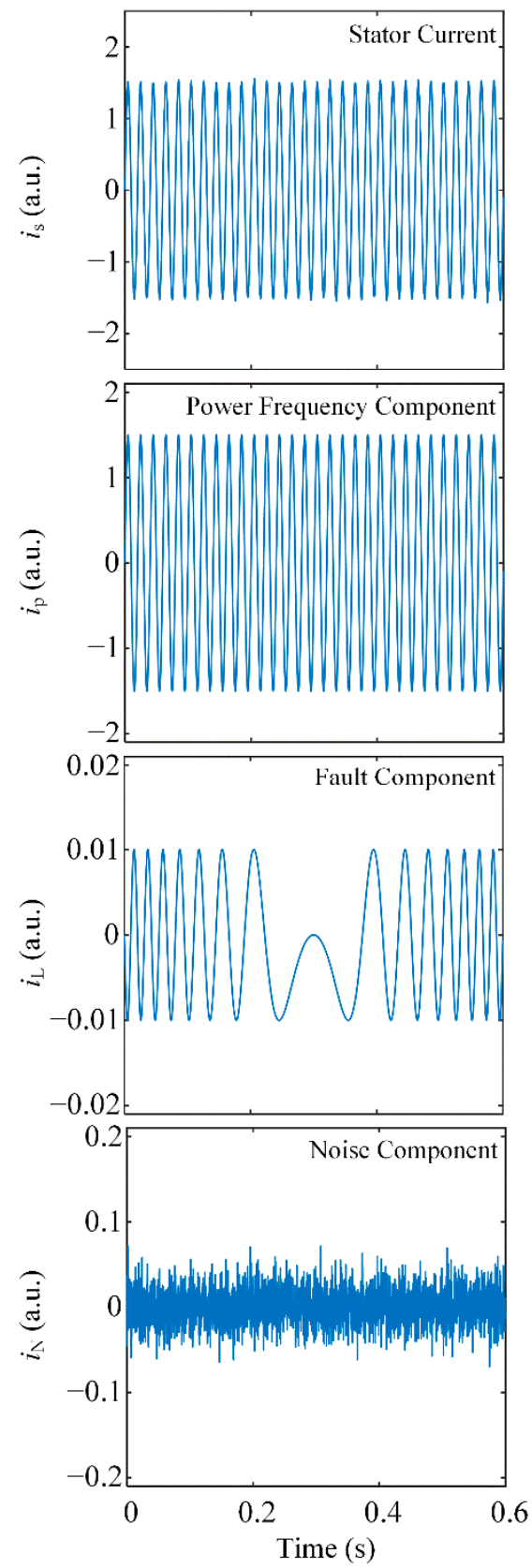

(a)

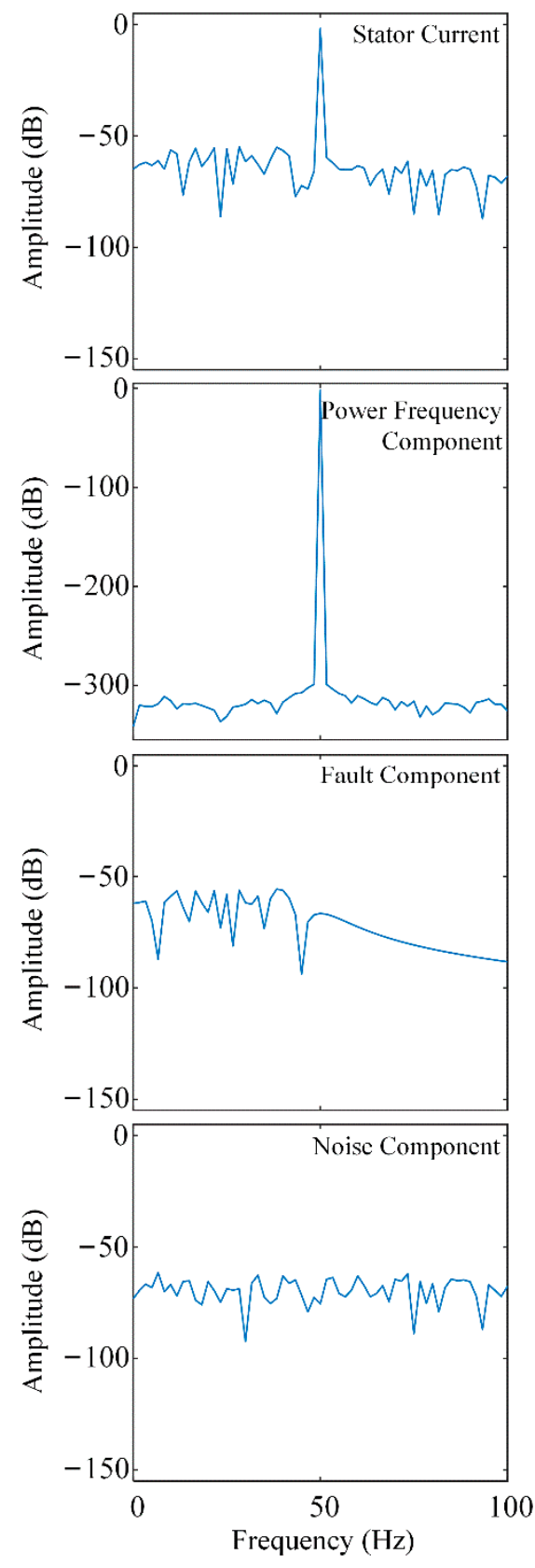

(b)

Figure 1. Time-domain waveform and power spectral density diagram of stator current and its components. (a) Current time domain waveform and (b) current power spectral density.

\section{Fault Diagnosis Method Based on Successive Variational Mode Decomposition}

In this section, the methodology of the proposed scheme is discussed. Firstly, the algorithm principle is explained in Section 3.1. Secondly, the parameter initialization of SVMD and the reconstruction of the fault component are introduced in Section 3.2. Thirdly, the broken bar faults detection based on the quadratic regression curve of the square value of the fault instantaneous frequency is put forward in Section 3.3. Finally, the proposed index for the severity of the broken bar faults is illustrated in Section 3.4. 


\subsection{Introduction to SVMD}

The principle of SVMD is to construct a variational problem and decompose the signal, its essence is the successive application of single-mode variational mode decomposition. Assuming that during the $h$ th SVMD decomposition, the stator current signal $i(t)$ is divided into two parts: the $h$ th mode $i_{h}(t)$ and the residual signal $i_{r h}(t)$, where $i_{r h}(t)$ consists of two parts, namely the undecomposed signal part $i_{u h}(t)$ and the sum of the previous $h-1$ modes. And those part is expressed as follows:

$$
\begin{gathered}
i(t)=i_{h}(t)+i_{r h}(t) \\
i_{r h}(t)=\sum_{k=1}^{h-1} i_{k}(t)+i_{u h}(t)
\end{gathered}
$$

The signal is decomposed into some modes possessing different frequency distribution by applying SVMD, and each mode is tightly distributed around its center frequency $\omega_{h}$, where $i_{h}(t)$ satisfies the following constraint:

$$
J_{1}=\min _{x_{h}}\left\{\left\|\frac{\partial}{\partial t}\left[\left(\delta(t)+\frac{j}{\pi t}\right) i_{h}(t)\right] \mathrm{e}^{-j \omega_{h} t}\right\|_{2}^{2}\right\}
$$

In order to reduce the spectrum overlap of $i_{h}(t)$ and $i_{r h}(t)$, the following constraints should also be met in the frequency domain:

$$
\begin{gathered}
\hat{J}_{2}=\min \left\{\sum_{k=1}^{h-1}\left\|\frac{i_{h}(\omega)}{\alpha\left(\omega-\omega_{k}\right)^{2}}\right\|_{2}^{2}\right\} \\
\hat{J}_{3}=\min \left\{\left\|\frac{i_{r h}(\omega)}{\alpha\left(\omega-\omega_{h}\right)^{2}}\right\|_{2}^{2}\right\}
\end{gathered}
$$

where $\alpha$ is the penalty factor, which is introduced for the Lagrange multiplier method.

In order to ensure the anti-interference of SVMD algorithm and the fidelity of signal decomposition, the penalty factor and Lagrange multiplier $\lambda(t)$ are added to obtain the following Lagrange function:

$$
\begin{aligned}
& L\left(i_{h}, \omega_{h}, \lambda\right)=\alpha J_{1}+J_{2}+J_{3}+\| i(t)-\left(i_{h}(t)+i_{u h}(t)\right. \\
& \left.+\sum_{k=1}^{h-1} i_{k}(t)\right) \|_{2}^{2}+\left\langle\lambda(t), i(t)-\left(i_{h}(t)+i_{u h}(t)+\sum_{k=1}^{h-1} i_{k}(t)\right)\right\rangle
\end{aligned}
$$

where $J_{1}$ and $J_{2}$ are $\hat{J}_{1}, \hat{J}_{2}$ in the time domain.

The optimal value is obtained through iterative search. SVMD converts the $h$-dimensional optimization problem of variational mode decomposition into $h$ one-dimensional optimization problems, thus significantly reducing the number of iterations and saving calculation time.

\subsection{SVMD Parameter Initialization and Fault Characteristic Signal Reconstruction}

In order to improve the speed of the algorithm and the accuracy of the decomposition results, the use of SVMD for adaptive decomposition requires to set a suitable initial value of the center frequency and a penalty factor in advance.

The initialization of the center frequency includes three types: (1) 0, (2) random setting, (3) the frequency $f_{\max }$ with the highest content in the mode. This paper takes $5.5 \mathrm{~kW}$ induction motor as an example for experiment, the parameters are shown in Table 1. The average running time is shown in Table 2 after multiple broken bar faults experiments. The shortest execution time is taken by SVMD when center frequency is initialized at the $f_{\max }$, so this article sets the center frequency to iterate from $f_{\max }$. Until the residual amount is less than the set value, this modal decomposition ends. 
Table 1. Electrical data of the induction motor.

\begin{tabular}{cc}
\hline The Motor Parameters & Value \\
\hline Motor Power & $5.5 \mathrm{~kW}$ \\
Voltage (rms) & $380 \mathrm{~V}$ \\
No. of poles & 3 \\
Number of stator slots & 36 \\
Number of rotor bars & 28 \\
Full load slip & $3 \%$ \\
\hline
\end{tabular}

Table 2. The influence of initial value of center frequency on SVMD decomposition time.

\begin{tabular}{cc}
\hline Initial Value & SVMD Time \\
\hline 0 & $6.717 \mathrm{~s}$ \\
Randomly & $8.098 \mathrm{~s}$ \\
$f_{\max }$ & $6.592 \mathrm{~s}$ \\
\hline
\end{tabular}

The penalty factor $\alpha$ is one of the most important parameters of SVMD. The larger the $\alpha$, the narrower the passband of modes. If $\alpha$ is too large, false modes will be generated; if $\alpha$ is too small, the bandwidth will be too large, which may cause mode mixing. Equation (4) makes the modes closely distributed around the center frequency, which means that SVMD is a decomposition that favors narrowband signals. However, Section 2 shows that the stator starting current contains a power frequency signal with a narrow bandwidth and the fault component with a wider bandwidth. In order to better extract the energy concentrate fault component from the stator current dominated by the power frequency, there would be a tradeoff considered in the setting of $\alpha$. If the fault component is decomposed into multiple small bandwidth signals, the utilization of a relatively larger $\alpha$ can give full play to the narrow-band decomposition advantages of SVMD and ensure the separation of fault component and power frequency component. Figure 2 shows the distribution curve of the energy value of the right part of the fault component and $\alpha$. In order to display the energy distribution under different faults in the same figure, the energy values in the Figure 2 are normalized based on the maximum value. It can be seen from Figure 2 that the energy amplitude of the fault current component is high in the range of $\alpha=50,000 \sim 150,000$, the energy value changes in a small range. The objective of the proposed method in this paper is to obtain energy concentrated fault signals. In the range of $\alpha=50,000 \sim 150,000$, the sensitivity of penalty factor parameter change to energy value change is not high. Therefore, according to the energy distribution of different fault shown in Figure 2, the maximum value of $\alpha$ is set to 100,000 in this paper.

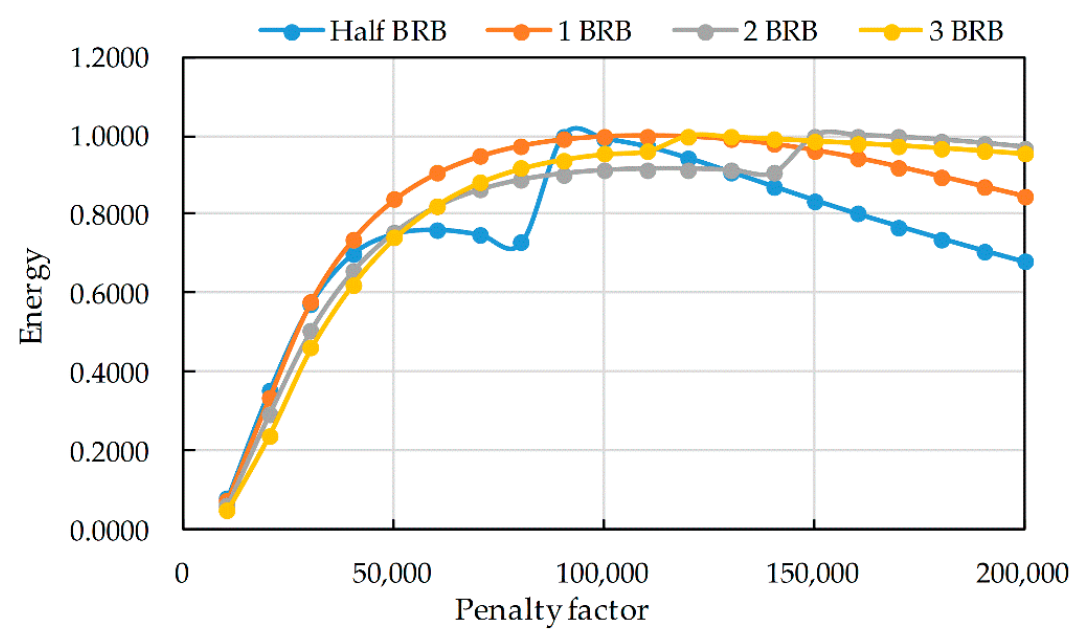

Figure 2. The relationship curve between the normalized value of the right part energy of the fault component and penalty factor $\alpha$. 
When $\alpha$ is large, SVMD is equivalent to a set of bandwidth filters, decomposing the signal into multiple small bandwidth signals, the starting fault component is a broadband signal, so the fault component decomposed by the SVMD will be distributed in multiple modes. Equation (5) minimizes the crossover between the modes. Therefore, the center frequency can be used to determine the position of the fault frequency in the frequency band. In order to make the energy of the fault signal concentrated to improve the accuracy of the diagnosis, this paper adds the modes whose center frequency below the power frequency to obtain the reconstructed fault component. The actual fault feature extraction results are shown in Section 5.2.

\subsection{Fault Detection Based on Quadratic Regression}

The slip $s$ varies from 1 to 0 in the starting time $t$, and when the power frequency $f$ is constant, the fault frequency $f_{\mathrm{b}}=|1-2 s| f$ displays a V-shape curve. The increasement rate of speed presents the tendency of "fast followed by slow", so the slip $s=0.5$ is in the second half of the starting process, that is, the lowest of frequency-time curve locates in the second half of starting process. As shown in Figure $3 \mathrm{a}$, the fault frequency $f_{\mathrm{b}}=|1-2 s| f$ and $t$ present an approximate piecewise linear relationship with $f_{\mathrm{b}}=0$ as the cut-off point during the starting process. The relationship between the $f_{\mathrm{b}}{ }^{2}$ and time $t$ is quadratic which is illustrated in Figure $3 \mathrm{~b}$. Therefore, the curve of $f_{\mathrm{b}}{ }^{2}$ with time can be established by the quadratic regression method. When the motor is healthy, the stator current includes power frequency components and noise, and the signal reconstructed by SVMD represents noise in this condition. The noise is randomly distributed, and the relationship between its instantaneous frequency square value and time does not follow the quadratic curve. If the quadratic regression method is exploited to healthy condition, the quadratic coefficient will be small.

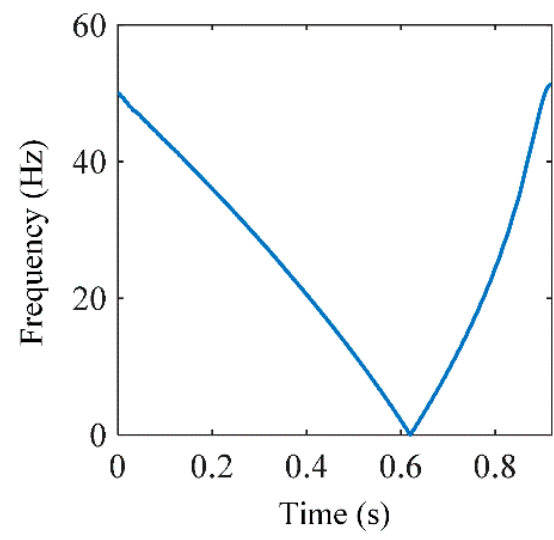

(a)

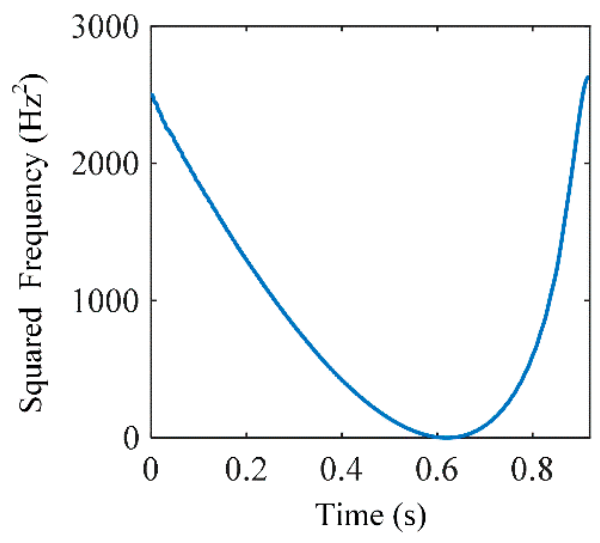

(b)

Figure 3. Fault characteristic instantaneous frequency during starting. (a) The curve of $f_{\mathrm{b}}$. (b) The curve of $f_{\mathrm{b}}^{2}$.

Carry out the broken bar faults experiment on the motor to verify the above theoretical analysis. The specific motor parameters are shown in Table 1 . The fault frequency squared values $f_{\text {bih }}{ }^{2}$ and $f_{\text {bsh }}{ }^{2}$ of partial broken rotor bar and healthy motors calculating from the reconstructed fault signal are illustrated in Figure $4 \mathrm{a}$, and the quadratic regression curves $f_{\text {bic }}{ }^{2}$ and $f_{\text {bsc }}{ }^{2}$ of the $f_{\text {bih }}{ }^{2}$ and $f_{\text {bsh }}{ }^{2}$ are shown in Figure 4 b. Figure 4 illustrates that only when the broken bar faults occur, the instantaneous frequency of the characteristic signal will exhibit the V-shaped trajectory as demonstrated in Figure 4. Even if the fault is partial broken rotor bar, the change trend of the curve can clearly distinguish the fault state and the health state of the motor.

This paper is based on the least square method to obtain the quadratic regression function of $f_{\mathrm{b}}{ }^{2}$ varying with time, and then diagnoses the broken bar faults according to 
the quadratic coefficient magnitude of the function. The opening size of the quadratic regression curve can indicate whether there is a V-shaped trajectory, and the quadratic coefficient can be used to indicate the opening size. When the quadratic coefficient is greater than the set threshold, it can be judged that the motor has the broken bar faults.

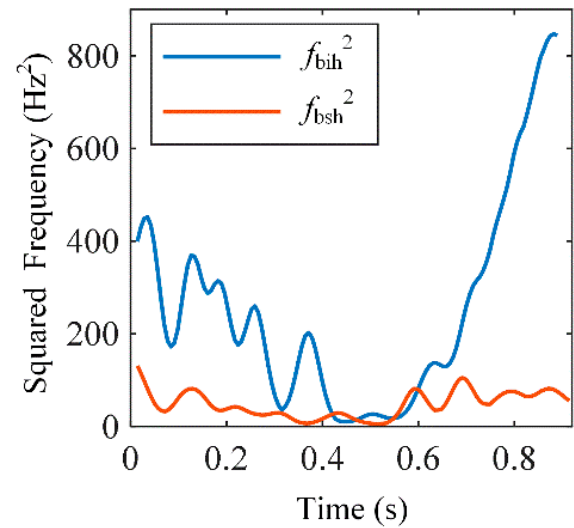

(a)

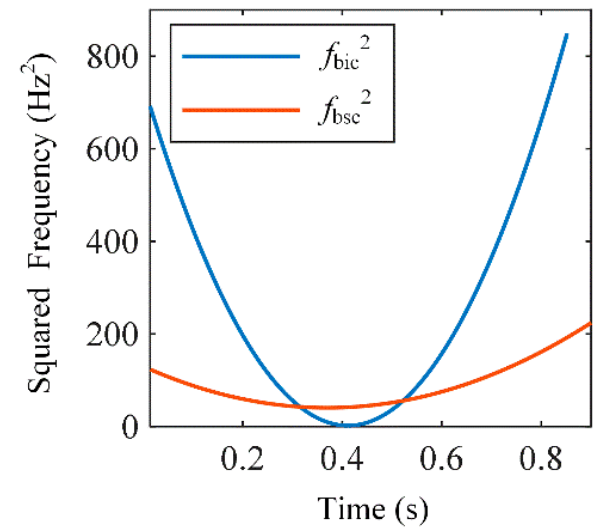

(b)

Figure 4. The faulty instantaneous frequency square value of partial broken rotor bar motors and healthy motors. (a) Experimental curve of $f_{\mathrm{b}}{ }^{2}$. (b) $f_{\mathrm{b}}{ }^{2}$ quadratic regression fitting curve.

\subsection{Fault Judgment Based on Quadratic Regression}

The quadratic coefficient can be used to diagnose whether the broken bar faults occur, but there is no clear relationship between quadratic coefficient and fault severity, so the quadratic regression method is not suitable for distinguishing the severity of the broken rotor bar. It is necessary to find a quantitative factor that can diagnosis the severity of the broken bar faults. The fault component signal gets more evident with the severity of broken bar faults increasing. The more serious the fault, the higher the energy that represents the fault severity degree of the signal. If the energy value of the fault signal is used as a quantitative factor to define the fault severity, an accurate early warning of the severity of the fault can be realized [28].

First, the $(t-f)$ distribution diagram of the fault component is drawn, and then energy integration on the $(t-f)$ region of the fault current is performed to obtain the energy value. Finally, the severity of the broken bar faults according to the energy value magnitude is distinguished. The calculation formula of the energy value $E_{r}$ in this paper is as follow:

$$
E_{r}=\int_{f_{1}}^{f_{2}} \int_{t_{1}}^{t_{2}} \omega(t, f) \mathrm{d} t \mathrm{~d} f
$$

where $f_{1}$ and $f_{2}$ are the upper and lower limits of frequency integration, respectively set to $0 \mathrm{~Hz}$ and $45 \mathrm{~Hz} ; t_{1}$ and $t_{2}$ are the upper and lower limits of time integration; and $\omega(t, f)$ is the fault frequency on the $(t-f)$ distribution diagram.

Figure 4 a shows that during the starting period, the changing trends of the left and right parts of the fault instantaneous frequency are different. The electromagnetic oscillation of the motor is severe at the start beginning, and there are low-frequency fluctuations in the stator current. In the meantime, the energy value of the right half of the fault component is higher than that of the left half, and it is not distorted by low-frequency interference [10]. Therefore, this paper takes the energy value of the right half of the fault component as a quantitative indicator of the severity of the fault. Setting the upper and lower limits of time $t_{1}$ and $t_{2}$ in Equation (8) as the start and end times of the right half of the fault component, the integral result is the energy value of the right half. 


\section{Successive Variational Mode Decomposition Based Broken Bar Faults Diagnosis Process}

In view of the fact that it is difficult to identify the broken bar faults under low slip, this paper proposes the fault diagnosis scheme based on SVMD to analyze the starting stator current. The specific process is shown in Figure 5, which is mainly divided into three stages. The first stage is the fault feature extraction. Firstly, the parameters of the SVMD are initialized, and then the stator starting current is decomposed into a series of modes by SVMD. Finally, the modes whose center frequency was below the power frequency were added together to obtain the reconstructed the fault component. The second stage is fault diagnosis. Firstly, calculating the instantaneous frequency of the fault component, and then getting the quadratic regression function of frequency square value. Finally, diagnosing the fault according to the magnitude of the quadratic coefficient, if there are the broken bar faults, issuing the fault warning. The third stage is the quantification of failure degree. Firstly, the $(t-f)$ distribution diagram of the fault component is drawn, and then the $(t-f)$ region where the fault signal is located according to Equation (8) is integrated to obtain the energy value which is representing the severity of the fault. Finally, the severity of the broken bar faults according to the magnitude of the energy is determined.

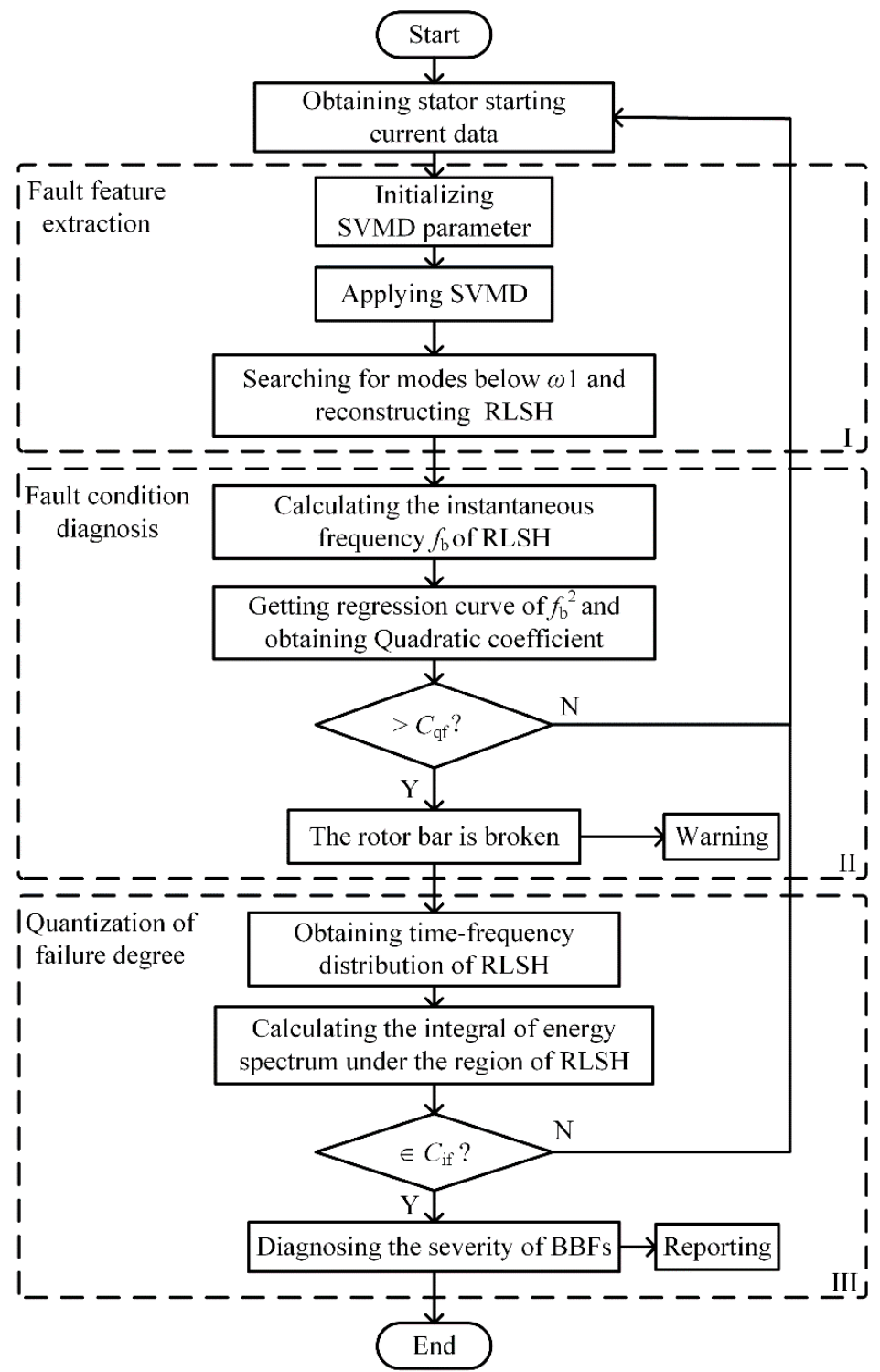

Figure 5. Flow chart of broken bar faults diagnosis, where RLSH is the right part of the fault component and BBFs is the broken bar faults. 


\section{Experimental Setup}

\subsection{Experimental Platform}

The proposed method has been applied to the analysis of a 5.5-kW 50- $\mathrm{Hz} \mathrm{IM}$, whose parameters are given in the Table 1. The experimental equipment is shown in Figure 6a, including a power supply system, a data acquisition system, and an experimental motor. The power supply system includes a voltage regulator that regulates the power supply voltage of the motor and an E36313A stabilized DC power supply that supplies power to the sensors. The data acquisition system includes IT 200-S current sensor, DHN-200 torque sensor, DLM4056 oscilloscope and signal switching circuit. Experiments have been carried out under five different fault conditions: healthy, partial broken rotor bar, one broken rotor bar, two broken rotor bars, and three broken rotor bars. The broken rotor bars are obtained by drilling holes, as shown in Figure 6b. In all experiments, the operating conditions are identical: the supply voltage is $139 \mathrm{~V}$ for preventing the experimental system from excessive surge current and ensuring safety in starting period, the motor is started at no load, and the sampling frequency of the starting current is $5 \mathrm{kHz}$. The proposed method is applied to experimental current signal under five different fault conditions, among them the starting current of the partial broken bar faults is shown in Figure 7.

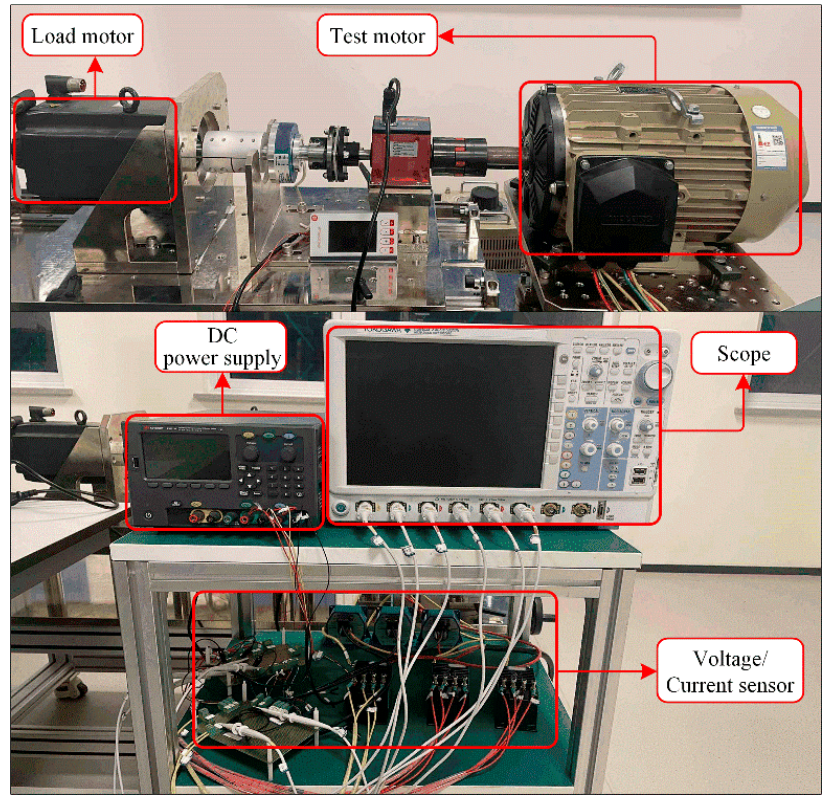

(a)

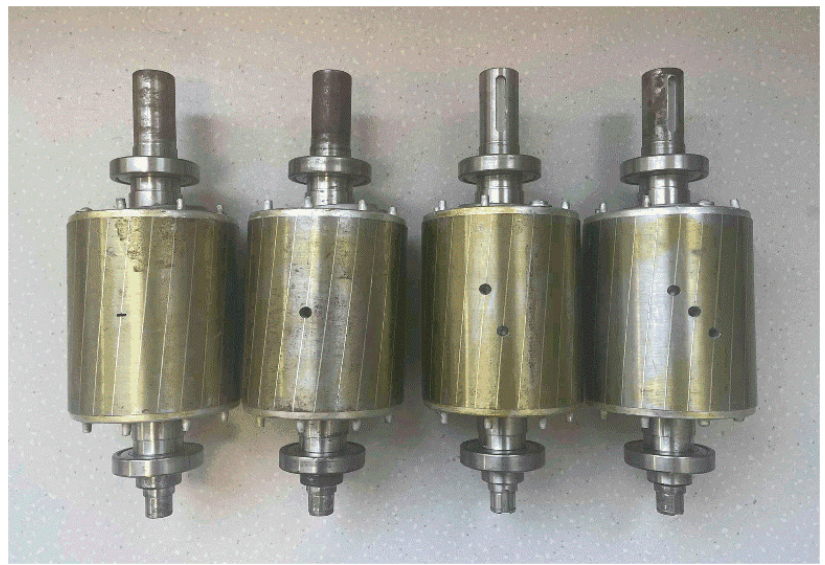

(b)

Figure 6. Experiment platform: (a) experimental equipment; (b) faulty rotors. 


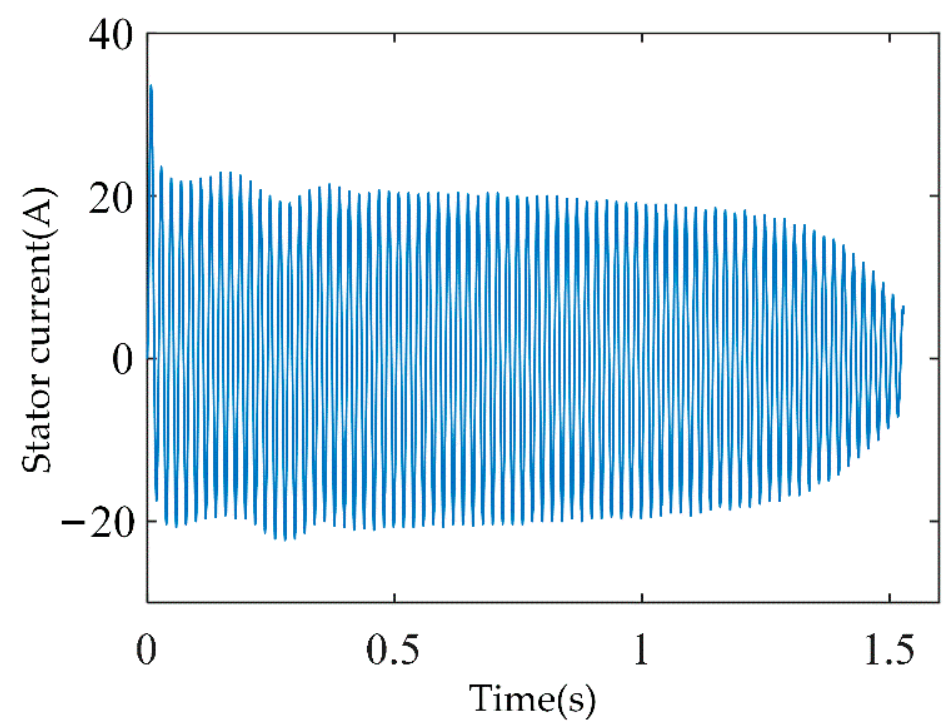

Figure 7. The starting current of the partial broken bar faults.

\subsection{Validation of Successive Variational Mode Decomposition Method}

In order to verify the effectiveness of the method proposed in this paper to obtain reconstructed fault signals based on SVMD, the method is compared with other methods by applying to the starting current of the partial broken rotor bar experiment shown in Figure 7 , and the $(t-f)$ distribution of the processing results is shown in Figure 8a. Related to this, the colored bars on the $(t-f)$ distribution diagram represent different energy densities. Yellow indicates higher densities, which means higher severity of failure. The other transforms (empirical wavelet transform, empirical mode decomposition) are applied to the same signal, and the consequences are illustrated in Figure 8b,c. Comparing the three processing outcomes, it can be found that the resolution of the right half of the fault component trajectory using empirical wavelet transform is misty whether or not noise is added. As the additive noise increases, the right half of the fault component trajectory in empirical mode decomposition becomes blurred. In contrast, SVMD displays a clear the right half of the fault component trajectory, and can also obtain energy-intensive the right half of the fault signal under the condition of aggravated noise. Therefore, the method of reconstructing fault signal based on SVMD proposed in this paper is suitable for the diagnosis of the broken bar faults.

The result of SVMD decomposes the stator starting current under the partial broken bar faults condition is shown in Figure 9a, where mode 0 represents the starting current signal, and modes 1 to 5 represent the modes obtained by SVMD decomposition of the stator current. It can be seen from Figure 9a that both mode 1 and mode 2 present the broken bar faults characteristics as illustrated in Figure 1, and the center frequencies are $5.9 \mathrm{~Hz}$ and $38.3 \mathrm{~Hz}$, respectively. Therefore, the reconstructed fault components are obtained by adding the two modes. For the purpose of avoiding the end effect of SVMD decomposition, $30 \%$ to $90 \%$ of the current signal is intercepted for fault detection, and the consequence is described in Figure 9b. 

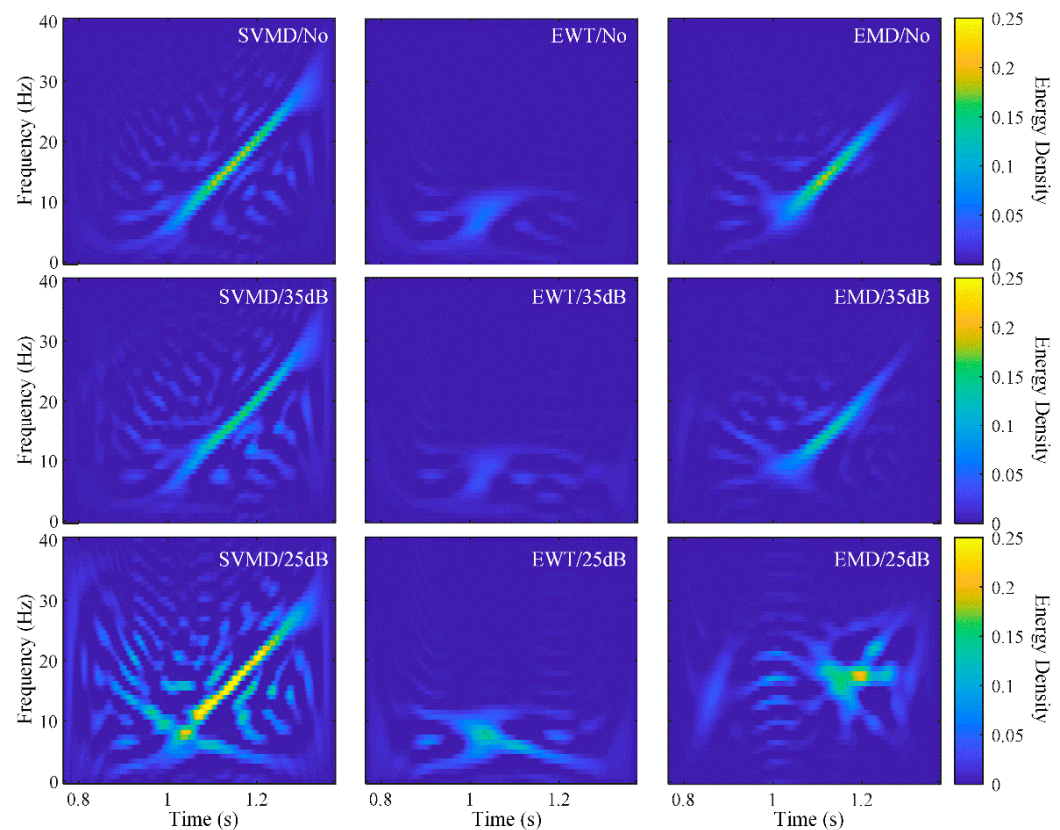

(a) SVMD

(b) EWT

(c) EMD

Figure 8. $(t-f)$ distribution of fault characteristic signals of partial broken rotor bar processed by different methods. Where No is the representation of no additional noise, $35 \mathrm{~dB}$ and $25 \mathrm{~dB}$ represent the SNR of $35 \mathrm{~dB}$ and $25 \mathrm{~dB}$ are added to the original signal. EMD is empirical mode decomposition, EWT is empirical wavelet transform.

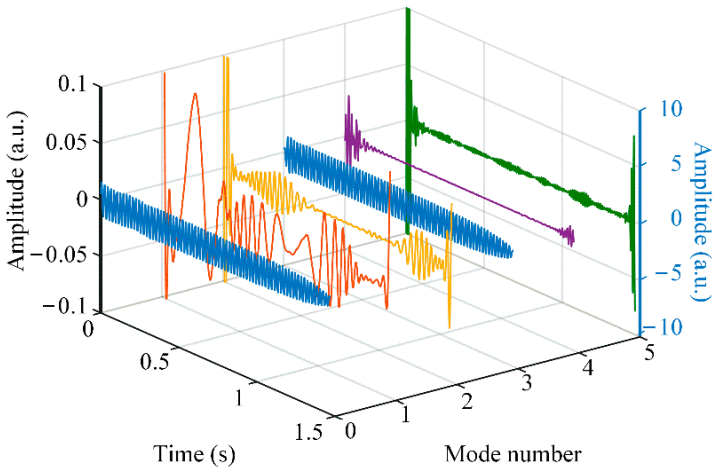

(a)

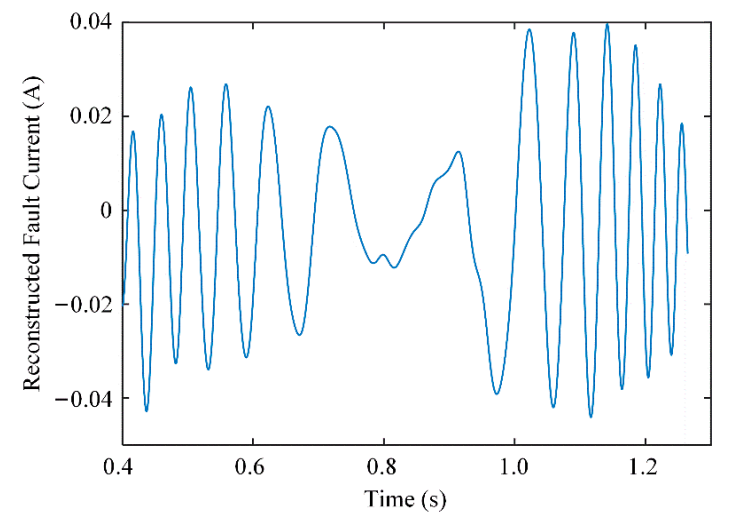

(b)

Figure 9. (a) SVMD decomposition diagram of stator starting current when the bar is partial broken. (b) Reconstructed fault characteristic current. 


\subsection{Fault Diagnosis}

As discussed before, SVMD has a good resolution in representing the fault frequency. In addition, effective pattern recognition technology is needed to distinguish the fault frequency in $(t-f)$ plane. After obtaining the reconstructed fault current, then calculating its instantaneous frequency $f_{\mathrm{b}}$, the quadratic regression curve of $f_{\mathrm{b}}{ }^{2}$ is achieved by the least square method. Figure 10 illustrates the $f_{\mathrm{b}}{ }^{2}$ curve of the induction motor under healthy (Healthy), partial broken rotor bar (Half BRB), one broken rotor bar (1 BRB), two broken rotor bars (2 BRB) and three broken rotor bars (3 BRB) conditions. The solid line and the dotted line, respectively, represent the square value curve of the $f_{\mathrm{b}}$ and the quadratic regression fitting curve of the $f_{\mathrm{b}}$. It can be seen from Figure 10 that when the motor has broken bar faults, the fitting curve presents obvious quadratic function characteristic, indicating the linear relationship between $f_{\mathrm{b}}$ and time during the starting process. However, when the motor is in a healthy state, the quadratic function feature of the fitting curve is extremely weak, indicating that $f_{\mathrm{b}}$ has a wireless relationship with time (that is, there is no $\mathrm{V}$-shaped characteristic and no broken bar faults of the motor).

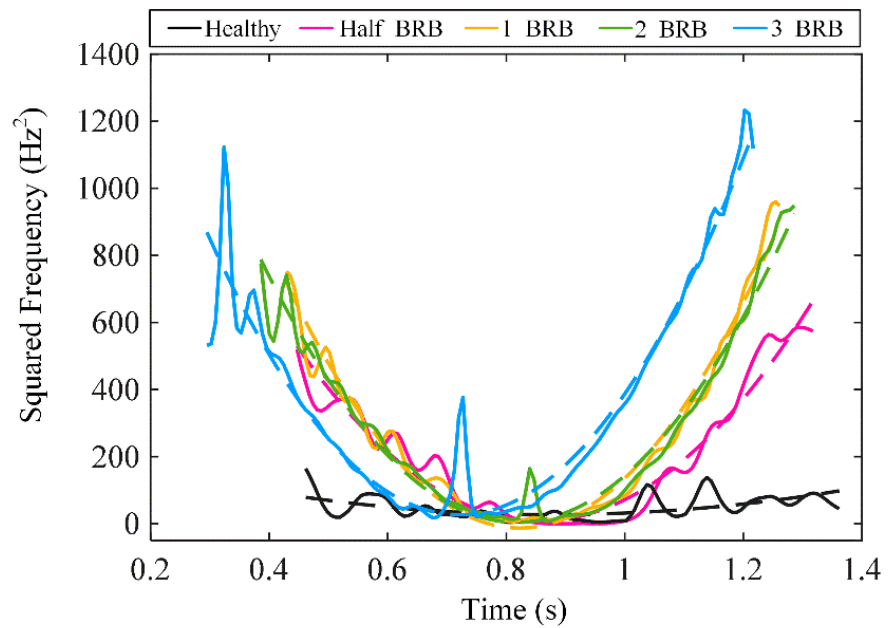

Figure 10. Fault characteristic frequency square curve of starting current.

This paper takes the quadratic coefficient of the quadratic regression curve to detect the broken bar faults, and performs 10 groups of experiments on the induction motor under five different broken rotor bar conditions. The mean and standard deviation of the quadratic coefficients obtained in the experiment are instructed in Table 3. It can be found that the quadratic coefficients of healthy motor and that of broken rotor bars motor have a large degree of differentiation, so they can be employed to fault diagnosis. In this paper, the mean value and standard deviation of the healthy motor are applied to set the fault threshold as described in Equation (9). When the quadratic coefficient of the quadratic regression curve of $f_{\mathrm{b}}{ }^{2}$ is greater than $C_{q f}$, it is detected as the broken bar faults. Setting $C_{q f}$ in this way ensures a minimum of $99.7 \%$ effectiveness during the classification process.

$$
C_{q f}=\mu_{1}+3 \sigma_{1}
$$

where $\mu_{1}$ and $\sigma_{1}$ are the mean and standard deviation of the healthy motor.

Table 3. Mean and standard deviation of quadratic coefficients.

\begin{tabular}{ccc}
\hline Motor State & Mean & Standard Deviation \\
\hline Healthy & 594 & 558 \\
Half BRB & 4200 & 170 \\
1 BRB & 4408 & 208 \\
2 BRBs & 4268 & 107 \\
3 BRBs & 4927 & 188 \\
\hline
\end{tabular}




\subsection{Quantification of Failure Severity}

As shown in Table 3, the magnitude of the quadratic coefficient can be practiced to diagnosis the broken bar faults, but the severity of the broken bar faults cannot be distinguished. Therefore, this paper takes the energy of the right part of the fault component as the fault quantification index to quantify the severity of the fault, so as to provide early warning of the broken bar faults.

The $(t, f)$ distribution of the right half of the fault component under different broken rotor bar conditions are shown in Figure 11. It can be found that the energy density of the right half of the fault component increases with the aggravation of the fault. The energy of the right half of the fault component can be calculated using Equation (8), and the mean $(\mu)$ and standard deviation $(\sigma)$ of the right half of the fault component energy of the 10 experiments is illustrated in Table 4 . The fault threshold range is set to $[\mu-3 \sigma, \mu+3 \sigma]$ to ensure that the accuracy of the fault severity discrimination is above $99.7 \%$. It can be seen from Table 4 that the right half of the fault component energy scope of healthy and partial broken bar faults overlap, which explains the necessity of using the quadratic regression method to judge the fault. However, the energy ranges of different adjacent broken rotor bars do not overlap each other and have a high degree of differentiation, which proves that the method proposed in this paper can diagnose the severity of the broken bar faults.

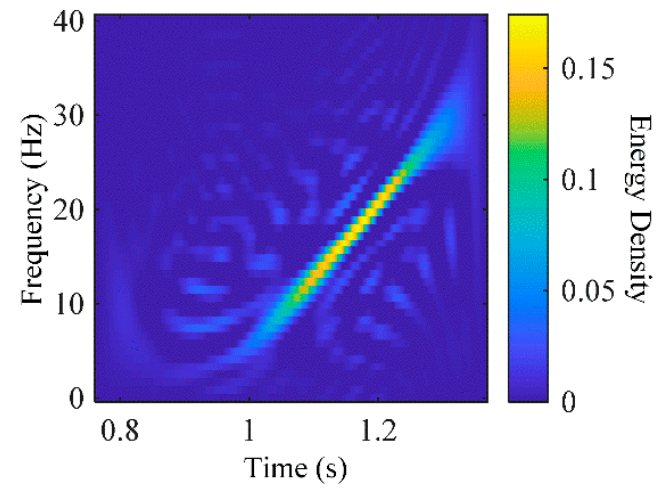

(a)

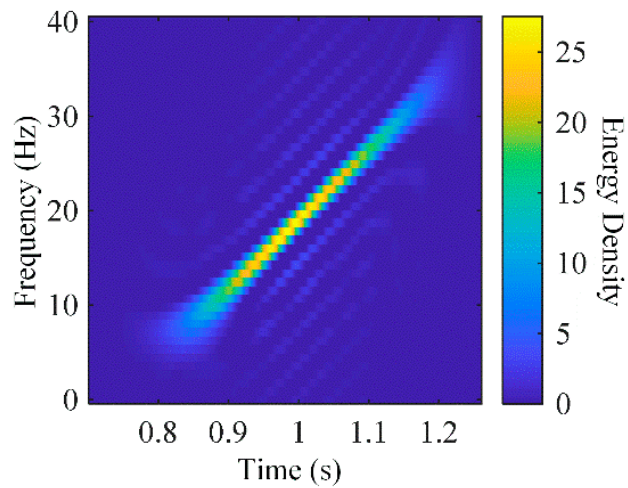

(c)

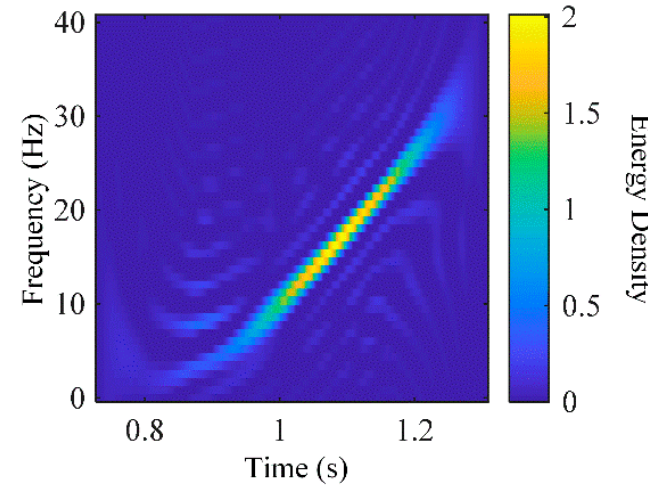

(b)

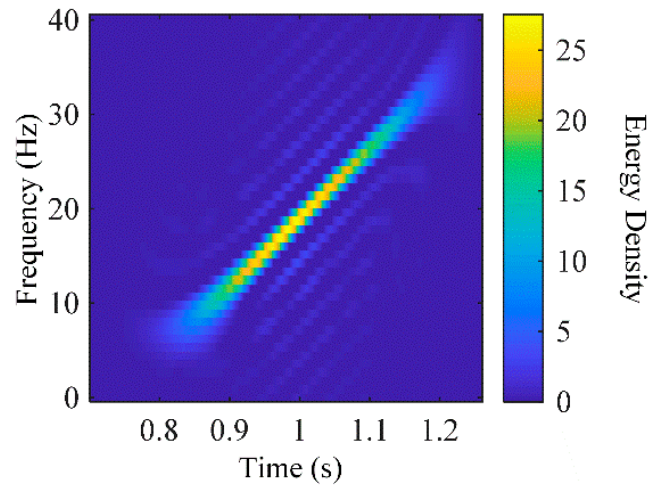

(d)

Figure 11. The right half of the fault component $(t, f)$ diagrams of different fault states. (a) Half broken rotor bar. (b) One broken rotor bar. (c) Two broken rotor bars. (d) Three broken rotor bars. 
Table 4. The mean and standard deviation of the right half of the fault component.

\begin{tabular}{cccc}
\hline Motor State & Mean $(\mu)$ & $\begin{array}{c}\text { Standard } \\
\text { Deviation }(\sigma)\end{array}$ & Regions \\
\hline Healthy & 0.0959 & 0.0247 & {$[0.02181,0.17353]$} \\
Half BRB & 0.1512 & 0.0389 & {$[0.02836,0.27419]$} \\
1 BRB & 1.5481 & 0.0848 & {$[1.29370,1.80252]$} \\
2 BRBs & 9.8031 & 0.3993 & {$[8.60501,11.0013]$} \\
3 BRBs & 20.957 & 1.2225 & {$[17.2902,24.6255]$} \\
\hline
\end{tabular}

\section{Conclusions}

According to the features that instantaneous frequency of the fault component of stator current changing with time during the starting period, this paper proposes a method to diagnosis broken bar faults and distinguish fault severity. The specific characteristics of the method are as follows:

- In this paper, SVMD is used to decompose the starting current into multiple smallbandwidth signals, and the fault components are reconstructed to maximize the energy of the fault signal, which realizes the signal noise reduction and improves the accuracy and rapidity of decomposition;

- Based on the linear relationship between the fault frequency and time in the starting process, the fault diagnosis of broken rotor bar is realized by comparing the quadratic coefficients of quadratic fitting curve of instantaneous frequency square of the fault component;

- According to the feature that the energy of the right half of the fault component signal increases with the severity of the broken bar faults, the severity of the fault can be determined by the energy of the right half of the fault component;

- By analyzing the starting current without measuring the speed, the proposed method avoids the problem of the fault frequency in the frequency domain analysis method being submerged by the power frequency when the slip rate is low.

Author Contributions: Conceptualization, X.L. and K.H.; methodology, Y.Y. and Z.Z.; software, X.L. and S.Z.; validation, X.L. and H.L.; formal analysis, H.L.; investigation, X.L., Y.Y. and H.L.; resources, K.H.; data curation, S.Z.; writing—original draft preparation, X.L.; writing-review and editing, T.S.; visualization, X.L.; supervision, T.S. and Z.Z.; project administration, Y.Y.; funding acquisition, T.S. All authors have read and agreed to the published version of the manuscript.

Funding: This research was funded by (1) the Science and Technology Project of Zhejiang Energy Group (No. 208020210582) and (2) the Fundamental Research Funds for the Central Universities (No. 2021FZZX001-13).

Institutional Review Board Statement: Not applicable.

Informed Consent Statement: Not applicable.

Data Availability Statement: Not applicable.

Conflicts of Interest: The authors declare no conflict of interest.

\section{References}

1. Xie, Y.; Shan, X.T.; Guo, J.P. The relationship study between field changes and faulty condition in squirrel-cage induction motor with broken bars fault. Proc. CSEE 2017, 37, 4222-4231.

2. Kliman, G.B.; Koegl, R.A.; Stein, J. Noninvasive detection of broken rotor bars in operating induction motors. IEEE Trans. Energy Convers. 1988, 3, 873-879. [CrossRef]

3. Gu, F.; Wang, T.; Alwodai, A.; Tian, X.; Shao, Y.; Ball, A.D. A new method of accurate broken rotor bar diagnosis based on modulation signal bispectrum analysis of motor current signals. Mech. Syst. Signal Process. 2015, 50, 400-413. [CrossRef]

4. Singh, G.; Naikan, V.N.A. Detection of half broken rotor bar fault in VFD driven induction motor drive using motor square current MUSIC analysis. Mech. Syst. Signal Process. 2018, 110, 333-348. [CrossRef]

5. Sun, L.; Xu, B. An improved method for discerning broken rotor bar fault and load oscillation in induction motors. Energies 2018, 11, 3130. [CrossRef] 
6. Garcia-Bracamonte, J.E.; Ramirez-Cortes, J.M.; de Jesus Rangel-Magdaleno, J.; Gomez-Gil, P.; Peregrina-Barreto, H.; AlarconAquino, V. An approach on MCSA-based fault detection using independent component analysis and neural networks. IEEE Trans. Instrum. Meas. 2019, 68, 1353-1361. [CrossRef]

7. Burriel-Valencia, J.; Puche-Panadero, R.; Martinez-Roman, J.; Sapena-Bano, A.; Pineda-Sanchez, M. Cost-effective reduced envelope of the stator current via synchronous sampling for the diagnosis of rotor asymmetries in induction machines working at very low slip. Sensors 2019, 19, 3471. [CrossRef]

8. Dias, C.G.; da Silva, L.C.; Alves, W.A.L. A histogram of oriented gradients approach for detecting broken bars in squirrel-cage induction motors. IEEE Trans. Instrum. Meas. 2020, 69, 6968-6981. [CrossRef]

9. Burriel-Valencia, J.; Puche-Panadero, R.; Martinez-Roman, J.; Sapena-Bano, A.; Pineda-Sanchez, M. Fault diagnosis of induction machines in a transient regime using current sensors with an optimized slepian window. Sensors 2018, 18, 146. [CrossRef]

10. Riera-Guasp, M.; Pineda-Sanchez, M.; Pérez-Cruz, J.; Puche-Panadero, R.; Roger-Folch, J.; Antonino-Daviu, J.A. Diagnosis of induction motor faults via Gabor analysis of the current in transient regime. IEEE Trans. Instrum. Meas. 2012, 61, 1583-1596. [CrossRef]

11. Ayon-Sicaeros, R.A.; Cabal-Yepez, E.; Ledesma-Carrillo, L.M.; Hernandez-Gomez, G. Broken-rotor-bar detection through STFT and windowing functions. In Proceedings of the 2019 IEEE Sensors Applications Symposium (SAS), Sophia Antipolis, France, 1-5 March 2019.

12. Pons-Llinares, J.; Riera-Guasp, M.; Antonino-Daviu, J.A.; Habetler, T.G. Pursuing optimal electric machines transient diagnosis: The adaptive slope transform. Mech. Syst. Signal Process. 2016, 80, 553-569. [CrossRef]

13. Pons-Llinares, J.; Antonino-Daviu, J.A.; Riera-Guasp, M.; Pineda-Sanchez, M.; Climente-Alarcon, V. Induction motor diagnosis based on a transient current analytic wavelet transform via frequency B-splines. IEEE Trans. Ind. Electron. 2010, 58, 1530-1544. [CrossRef]

14. Antonino-Daviu, J.A.; Riera-Guasp, M.; Folch, J.R.; Palomares, M.P.M. Validation of a new method for the diagnosis of rotor bar failures via wavelet transform in industrial induction machines. IEEE Trans. Ind. Appl. 2006, 42, 990-996. [CrossRef]

15. Cabal-Yepez, E.; Garcia-Ramirez, A.G.; Romero-Troncoso, R.J.; Garcia-Perez, A.; Osornio-Rios, R.A. Reconfigurable monitoring system for time-frequency analysis on industrial equipment through STFT and DWT. IEEE Trans. Ind. Inform. 2012, 9, 760-771. [CrossRef]

16. Martinez-Herrera, A.L.; Ledesma-Carrillo, L.M.; Lopez-Ramirez, M.; Salazar-Colores, S.; Cabal-Yepez, E.; Garcia-Perez, A. Gabor and the Wigner-Ville transforms for broken rotor bars detection in induction motors. In Proceedings of the 2014 International Conference on Electronics, Communications and Computers (CONIELECOMP), Cholula, Mexico, 26-28 February 2014.

17. Rajagopalan, S.; Restrepo, J.A.; Aller, J.M.; Habetler, T.G.; Harley, R.G. Nonstationary motor fault detection using recent quadratic time-frequency representations. IEEE Trans. Ind. Appl. 2008, 44, 735-744. [CrossRef]

18. Climente-Alarcon, V.I.C.E.N.T.E.; Antonino-Daviu, J.A.; Riera-Guasp, M.; Puche-Panadero, R.; Escobar, L. Application of the Wigner-Ville distribution for the detection of rotor asymmetries and eccentricity through high-order harmonics. Electr. Power Syst. Res. 2012, 91, 28-36. [CrossRef]

19. Valles-Novo, R.; de Jesus Rangel-Magdaleno, J.; Ramirez-Cortes, J.M.; Peregrina-Barreto, H.; Morales-Caporal, R. Empirical mode decomposition analysis for broken-bar detection on squirrel cage induction motors. IEEE Trans. Instrum. Meas. 2014, 64, 1118-1128. [CrossRef]

20. Valtierra-Rodriguez, M.; Amezquita-Sanchez, J.P.; Garcia-Perez, A.; Camarena-Martinez, D. Complete ensemble empirical mode decomposition on FPGA for condition monitoring of broken bars in induction motors. Mathematics 2019, 7, 783. [CrossRef]

21. Soualhi, A.; El Yousfi, B.; Razik, H.; Wang, T. A Novel Feature Extraction Method for the Condition Monitoring of Bearings. Energies 2021, 14, 2322. [CrossRef]

22. Gilles, J. Empirical wavelet transform. IEEE Trans. Signal Process. 2013, 61, 3999-4010. [CrossRef]

23. Kedadouche, M.; Thomas, M.; Tahan, A.J.M.S. A comparative study between Empirical Wavelet Transforms and Empirical Mode Decomposition Methods: Application to bearing defect diagnosis. Mech. Syst. Signal Process. 2016, 81, 88-107. [CrossRef]

24. Dragomiretskiy, K.; Zosso, D. Variational mode decomposition. IEEE Trans. Signal Process. 2013, 62, 531-544. [CrossRef]

25. Zou, D.; Ge, X. A Broken Rotor Bar Fault Diagnosis Approach Based on Singular Value Decomposition and Variational Mode Decomposition. In Proceedings of the 2019 IEEE Transportation Electrification Conference and Expo, Asia-Pacific (ITEC AsiaPacific), Seogwipo, Korea, 8-10 May 2019.

26. Bi, X.; Lin, J.; Tang, D.; Bi, F.; Li, X.; Yang, X.; Shen, P. VMD-KFCM algorithm for the fault diagnosis of diesel engine vibration signals. Energies 2020, 13, 228. [CrossRef]

27. Nazari, M.; Sakhaei, S.M. Successive variational mode decomposition. Signal Process. 2020, 174, 107610. [CrossRef]

28. Atta, M.E.E.D.; Ibrahim, D.K.; Gilany, M. Broken Bar Faults Detection under Induction Motor Starting Conditions Using the Optimized Stockwell Transform and Adaptive Time-Frequency Filter. IEEE Trans. Instrum. Meas. 2021, 70, 3518110. 